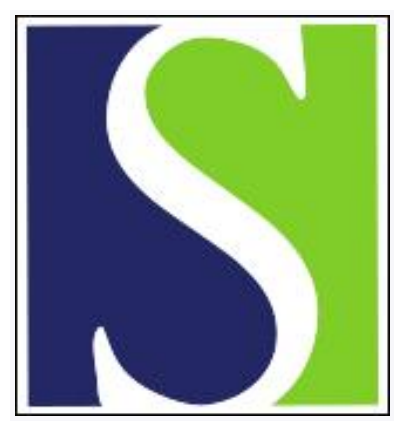

Scand J Work Environ Health 1981;7(1):38-44

https://doi.org/10.5271/sjweh.2568

Issue date: Mar 1981

A rapid method for the selective analysis of total urinary metabolites of inorganic arsenic.

by Norin $\mathrm{H}$, Vahter $\mathrm{M}$

Key terms: dimethylarsinic acid; exposure indicator; inorganic arsenic; methylarsonic acid; occupational exposure; occupational exposure; selective analysis; total urinary metabolite

This article in PubMed: www.ncbi.nlm.nih.gov/pubmed/7313608

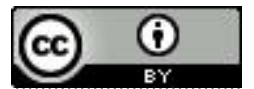




\title{
A rapid method for the selective analysis of total urinary metabolites of inorganic arsenic
}

\author{
by Harald Norin, BSc, Marie Vahter, MSP
}

\begin{abstract}
NORIN H, VAHTER M. A rapid method for the selective analysis of total urinary metabolites of inorganc arsenic. Scand $j$ work environ health 7 (1981) 38-44. Total urinary arsenic has traditionally been used for assessing occupational exposure to inorganic arsenic. However, dietary arsenic, especially from seafood, may greatly influence this value. This paper describes a fast and convenient method for routinely measuring the combined amount of inorganic arsenic, methylarsonic acid, and dimethylarsinic acid, which are the major urinary metabolites after exposure to inorganic arsenic. Organic arsenic compounds of marine origin are not biotransformed to inorganic arsenic or methylated arsenic acids to any significance in the human body. They do not produce arsines when treated with the reducing agent in the proposed method and will therefore not interfere with the measurements. The sensitivity, accuracy, and precision of the proposed method are sufficient for the determination of concentrations of arsenic normally found in the urine of nonexposed persons. The method is based on a commercially available hydride generation kit attached to an atomic absorption spectrophotometer.
\end{abstract}

Key terms: occupational exposure, exposure indicator, dimethylarsinic acid, methylarsonic acid.

Total urinary arsenic has traditionally been used for assessing occupational exposure to inorganic arsenic. However, dietary arsenic, especially from seafood, may greatly influence these measurements. Certain fish and crustaceans may contain an arsenic concentration of as much as $1 \mathrm{mmol} / \mathrm{kg}$, predominantly as organic arsenic compounds (16). Ingestion of seafood may result in total urinary arsenic levels of more than $10 \mu \mathrm{mol} / 1(0.8 \mathrm{mg} / \mathrm{l})(19,30)$, while persons without such exposure to arsenic usually have urinary levels in the range of $0.1-0.7 \mu \mathrm{mol} / 1(0.01-0.05 \mathrm{mg} / \mathrm{l})$ $(3,19)$. Total urinary arsenic is thus a useless indicator of occupational exposure if the intake of "fish arsenic" cannot be controlled.

1 National Institute of Environmental Medicine and the Departments of Environmental Hygiene and Toxicology, The Karolinka Institute, Stockholm, Sweden.

Reprint requests to: Ms Marie Vahter, National Institute of Environmental Medicine, Box 60208, S-104 01 Stockholm, Sweden.
Inorganic arsenic is methylated in vivo. After exposure to inorganic arsenic 50$70 \%$ of the arsenic excreted in urine is in the form of dimethylarsinic acid (DMA) $(8,22,24,32,33)$. Methylarsonic acid (MMA) and inorganic arsenic account for $10-20 \%$ each. Increased dose levels cause an increased excretion of inorganic arsenic and a corresponding decrease in the excretion of methylated forms $(28,32,33)$. Studies by Crecelius (8) and Cannon et al (6) indicate that organic arsenic of marine origin is not biotransformed in the human body but is excreted in the urine as such. Measurements of inorganic arsenic, MMA, and DMA in urine should therefore give a better estimate of exposure to inorganic arsenic than total urinary arsenic would. Smith et al (22) measured these metabolites, as well as total arsenic, in the urine of workers in a copper smelter. Inorganic trivalent arsenic, MMA, and DMA were all found to be better correlated with airborne arsenic than was the total urinary arsenic level. 
Braman \& Foreback (4) have described a method for speciating inorganic arsenic, MMA, and DMA in urine; the method employs the cold trapping of generated arsines in combination with atomic emission spectrometry. Other reported methods for selectively analyzing different arsenic compounds include arsine generation/ spectrophotometry (14), ion-exchange chromatography/differential pulse polarography (10), high pressure liquid chromatography/graphite furnace atomic absorption spectrophotometry (31), gas chromatography/emission spectrophotometry (23), and selective extraction with toluene/ atomic absorption spectrophotometry (AAS) (5).

Differentiating between the different urinary metabolites of arsenic is complicated, time consuming, and, therefore, not suitable for routine analysis in industry. The ideal method should allow arsenic concentrations of $0.05 \mu \mathrm{mol} / 1$ to be determined without interference from "fish arsenic." For the frequent control of exposed workers it should be simple and rapid without necessarily entailing detailed separation. The objective of this study was to develop such a method. For this purpose a commencially available hydride generation kit attached to an atomic absorption spectrophotometer was used.

\section{Material and methods}

\section{Experimental design}

The proposed methods gives measurements of the combined amount of inorganic arsenic, MMA, and DMA. It is referred to as method I throughout this report. Accuracy, precision, sensitivity, and interference from "fish arsenic" and selenium have been investigated.

Interference from arsenic compounds of marine origin was studied through the addition of synthetic arsenobetaine and arsenocholine to urine samples. Arsenobetaine has been demonstrated to be present in rock lobster, dusky shark, and western sand whiting (6). It was synthesized according to Edmonds et al (9). Arsenocholine, a trimethyl(2-hydroxyethyl) arsonium ion which has been suggested as a possible form of arsenic in Daphnia lipids (12), was synthesized according to
Samaan (20). The identities of the synthesized compounds were confirmed from melting point measurements, nuclear magnetic resonance spectroscopy, and mass spectra. Arsenic was also measured in the urine of two human subjects before and after they ingested shrimp. The subjects were told not to eat fish or crustaceans during the week before the intake of shrimp and for $3 \mathrm{~d}$ thereafter.

The most important interferences in the arsine generation technique are transition metals and compounds which form hydrides with sodium borohydride (21). Such interferences are not significant at the concentrations normally found in human urine, except maybe for selenium. The effect of selenite on the measurement of arsenic was therefore investigated.

Unless otherwise stated, urine samples from workers exposed to arsenic in a smelter and having no known exposure to "fish arsenic" were used. The samples were preserved by the addition of concentrated hydrochloric acid $(\mathrm{HCl})(1 \mathrm{mI}$ to $100 \mathrm{ml}$ of urine) and stored in polyethylene bottles at $4^{\circ} \mathrm{C}$.

\section{Apparatus}

A Perkin-Elmer 360 atomic absorption spectrophotometer (AAS), equipped with an electrodeless discharge lamp (EDL), was used for detecting arsenic hydrides. The resonance line at $193.8 \mathrm{~nm}$ was used. A single-channel integrating recorder (linear model 252) was used for peak recording and peak area measurements.

\section{Standards and reagents}

Standard solutions were prepared from sodium arsenate $\left(\mathrm{Na}_{2} \mathrm{HAsO}_{4} \cdot 7 \mathrm{H}_{2} \mathrm{O}\right.$, Merck), monomethylarsonic acid $(63 \%$, PfalzBauer Inc, USA), or dimethylarsinic acid (99\% pure "Baker" grade from JT Baker Chemicals, The Netherlands). Sodium borohydride (Merck) solutions were passed through $0.45 \mu \mathrm{m}$ poresize filters of the cellulose acetate membrane type to improve stability (13). Buffer solutions were prepared from oxalic acid (analytical purity, Merck).

\section{Decomposition procedures}

Measuring total arsenic requires the decomposition of the organic material in the 
sample. Wet digestion was used for standard reference material, orchard leaves of the National Bureau of Standards (NBS) (18). Ten milliliters of a mixture of nitric acid, perchloric acid, and sulfuric acid $(62.5: 22.5: 15)$ were added to a 0.5 -g sample, whereafter the sample was allowed to boil under reflux $\left(110^{\circ} \mathrm{C}\right)$ for about 30 $\min$. The temperature was then increased to about $250^{\circ} \mathrm{C}$ for the complete evaporation of the nitric and perchloric acids. To the residual sulfuric acid solution was added $25 \mathrm{ml}$ of $3 \mathrm{M} \mathrm{HCl}$.

Total arsenic in urine was determined after the urine was dry ashed according to Uthe et al (27).

\section{Analytical methods}

Determination of the combined amount of inorganic arsenic, methylarsonic acid and dimethylarsinic acid - Method I. A commercially available Mercury/Hydride System (MHS-10 Perkin-Elmer) attached to the AAS was used to determine the combined amount of inorganic arsenic, MMA, and DMA. Aliquots of $0.5-5 \mathrm{ml}$ of urine were analyzed directly without any pretreatment. If needed, deionized water was added to the urine to give a final volume of about $5 \mathrm{ml}$ in the reaction chamber. Adding $0.5 \mathrm{ml}$ of concentrated $\mathrm{HCl}$ decreased the $\mathrm{pH}$ to $1-1.5$. Sodium borohydride [ $4 \%$ in $0.05 \mathrm{M}$ sodium hydroxide $(\mathrm{NaOH})]$ was added to generate the arsines, which were passed to the AAS and detected. All the results are based on peak area measurements.

Speciation of inorganic arsenic, methylarsonic acid and dimethylarsinic acid Method II. A modification of the method, described by Braman \& Foreback (4) and Andreae (1) involving cold trapping of generated arsines and detection by AAS, was used to speciate the inorganic arsenic, MMA and DMA. First 0.5-5 ml of urine (not pretreated) was diluted with $50 \mathrm{ml}$ of deionized water in the reaction chamber. The $\mathrm{pH}$ was adjusted to $1-1.5$ by an addition of $5 \mathrm{ml}$ of oxalic acid $(10 \%$ wt/vol). Helium, used as a carrier gas, was passed through the system for about $1 \mathrm{~min}$ to remove oxygen; whereafter $6 \mathrm{ml}$ of sodium borohydride $(4 \%$ in $0.05 \mathrm{M}$ $\mathrm{NaOH}$ ) was added. Generated arsines were trapped in a $\mathrm{U}$ tube immersed in liquid nitrogen. When the $U$ tube was removed from the liquid nitrogen, arsines of inorganic arsenic, MMA, and DMA were volatilized successively due to differences in their boiling points. Arsines were transported via the carrier gas to the detector (AAS).

Water solutions of arsenate, MMA, and DMA were used as standards for peaks representing inorganic arsenic, MMA, and DMA, respectively. All the results were based on peak area measurements.

Ion-exchange chromatographic separation of inorganic arsenic, methylarsonic acid and dimethylarcinic acid - Method III. Method III has earlier been described by Tam et al $(25,26)$. One milliliter of urine was applied to a strong cationic ion-exchange resin (AG 50W $-\mathrm{X} 8,100-200$ mesh). Inorganic arsenic, MMA, and DMA were eluated successively with $0.5 \mathrm{M} \mathrm{HCl}$, deionized water and $4 \mathrm{M}$ ammonia.

\section{Results}

\section{Accuracy}

The results of the proposed method (method I) were compared with the results of method II [method of Braman \& Foreback (4)] With the latter method the sum of inorganic arsenic, MMA, and DMA can be calculated from the individual values of the three compounds. The identity of the compounds giving the three peaks in method II was checked through the introduction of a preseparation step [method III (26)]; whereafter the fractions containing inorganic arsenic, MMA, and DMA were analyzed separately with method II. The peak areas obtained with and without preseparation were compared for each compound.

Table 1 shows the comparison of methods I and II for three urine samples. It can be seen that the results of the two methods agree very closely. The mean values differed by less than $7 \%$. The peak areas and retention times obtained with method II, when urine was analyzed directly and after preseparation with method III, were almost identical. This result confirms that the three peaks corresponded to inorganic arsenic, MMA, and DMA, respectively. It also confirms that meth- 
od I measures the sum of inorganic arsenic, MIMA, and DIMA.

The peak areas and peak heights obtained with method I were studied in relation to the chemical forms of arsenic. Standard solutions containing $25 \mathrm{ng}$ of arsenic in the form of arsenate, MMA, or DMA were analyzed, and the peak areas per micromole of arsenic were found to be independent of chemical form. The peak heights, however, varied to a great extent. Any of the arsenic compounds studied can thus be used as a standard for measuring the sum of inorganic arsenic, MMA, and DMA provided that peak areas are recorded. Sodium arsenate was used as the standard throughout this study.

The recovery of arsenic added to urine samples was determined as a validation of the concentrations of arsenic obtained with method I. A mixture of arsenate, MMA, and DMA $(20,15$ and $65 \%$, respectively, corresponding to normal distribution in urine) was added to the urine. Table 2 shows that recovery was almost complete within the range $0.7-5 \mu \mathrm{mol} / 1$ $(0.05-0.4 \mathrm{mg} / \mathrm{l})$.

The arsenic concentration in NBS orchard leaves (18) was analyzed with method I. The organic material in the sample was decomposed by wet digestion prior to analysis. The arsenic level found was 140 $\mu \mathrm{mol} / \mathrm{kg} \quad(10.5 \mathrm{mg} / \mathrm{kg})$ of dry weight (mean of two determinations), which should be compared with the certified value of $10 \pm 2 \mathrm{mg} / \mathrm{kg}$ (18)..$^{2}$

\section{Precision}

The precision of the method was determined by repeated analysis of the same urine samples; it has been expressed as the standard deviation. Table 1 shows that method I had a somewhat better precision than method II, only about an $8 \%$ relative standard deviation at the low concentration.

\section{Sensitivity}

Sensitivity was measured as the amount of arsenic giving $1 \%$ absorption or 0.0044 absorption units. Method I gave a sensi-

2 The National Bureau of Standards lists its certified values in milligrams per kilogram only. tivity of $0.008 \mu \mathrm{mol}$ equal to about $0.001 \mu \mathrm{mol}$ of arsenic per liter.

\section{Interference}

Arsenobetaine and arsenocholine were added to urine in concentrations of 33 $\mu \mathrm{mol} / 1$. The results of method I, given in table 3, show that the added compounds did not interfere with the measurements. Table 4 presents the concentrations of ar-

Table 1. Total amount of inorganic arsenic methylarsonic acid (MMA) and dimethylarsinic acid (DMA) in three urine samples as determined with method I and II. The values for method II have been calculated from the results of the individual compounds. Figures represent micromoles of arsenic per liter of urine (mean \pm $\mathrm{SD}) . \quad(\mathrm{N}=$ number of determinations $)$

\begin{tabular}{lccc}
\hline \multirow{2}{*}{$\begin{array}{l}\text { Urine } \\
\text { sample }\end{array}$} & $N$ & \multicolumn{2}{c}{$\begin{array}{c}\text { Inorganic arsenic }+ \\
\text { MMA }+ \text { DMA }\end{array}$} \\
\cline { 3 - 4 } & & Method 1 & Method II \\
\hline A & 6 & $0.33 \pm 0.03$ & $0.31 \pm 0.04$ \\
B & 4 & $3.80 \pm 0.10$ & $3.75 \pm 0.27$ \\
C & 2 & $1.92 ; 2.13$ & $2.05 ; 2.09$ \\
\hline
\end{tabular}

Table 2. Recovery of arsenic added to urine as a mixture of inorganic arsenic, methylarsonic acid and dimethylarsinic acid $(20,15$ and $65 \%$, respectively). The values represent the mean of two determinations with method I.

\begin{tabular}{lrr}
\hline \multirow{2}{*}{$\begin{array}{l}\text { Added arsenic } \\
(\mu \mathrm{mol} / \mathrm{I})\end{array}$} & \multicolumn{2}{c}{ Recovery } \\
\cline { 2 - 3 } & $\mu \mathrm{mol} / \mathrm{I}$ & $\%$ \\
\hline & & \\
0.66 & 0.11 & 98 \\
1.33 & 0.65 & 97 \\
2.67 & 1.29 & 104 \\
5.33 & 2.79 & 100 \\
\hline
\end{tabular}

Table 3. Determination of the sum of inorganic arsenic, methylarsonic acid (MMA) and dimethylarsinic acid (DMA) in urine in the presence of arsenobetaine, arsenocholine or selenite. The values represent the mean of two determinations.

\begin{tabular}{lc}
\hline Addition & $\begin{array}{c}\text { Measured } \\
\text { inorganic arsenic } \\
\text { MMA + DMA } \\
(\mu \mathrm{mol} / \mathrm{l})\end{array}$ \\
\hline 0 & 0.69 \\
Arsenobetaine $(33 \mu \mathrm{mol} / \mathrm{l})$ & 0.71 \\
Arsenocholine $(33 \mu \mathrm{mol} / \mathrm{l})$ & 0.65 \\
Selenite $(1.6 \mu \mathrm{mol} / /)$ & 0.68 \\
Selenite $(3.2 \mu \mathrm{mol} / \mathrm{l})$ & 0.69 \\
\hline
\end{tabular}


Table 4. Combined amount of inorganic arsenic, methylarsonic acid (MMA) and dimethylarsinic acid (DMA), as well as total arsenic, in human urine before and after ingestion of shrimp. The figures represent the mean of two subjects.

\begin{tabular}{lcccccc}
\hline Urine & $\begin{array}{c}\text { Inorganic arsenic }+ \\
\text { MMA+DMA, method I } \\
(\mu \text { mol/I) }\end{array}$ & & \multicolumn{2}{c}{$\begin{array}{c}\text { Total arsenic, method I } \\
\text { after dry ashing } \\
(\mu \mathrm{mol} / \mathrm{I})\end{array}$} \\
\cline { 2 - 3 } \cline { 5 - 6 } & Subject A & Subject B & & Subject A & Subject B \\
\hline Before exposure & 0.09 & 0.17 & & 0.25 & 0.29 \\
Day 1 & 0.17 & 0.33 & & 16.4 & 18.3 \\
Day 2 & 0.19 & 0.20 & & 5.2 & 2.4 \\
Day 3 & 0.16 & 0.21 & & 2.5 & 2.3 \\
\hline
\end{tabular}

senic (method I) in the urine of two subjects before and after they ingested seafood. The urinary excretion of inorganic and methylated arsenic compounds did not change to any significance, although the total urinary arsenic increased to 18 $\mu \mathrm{mol} / 1$.

Sodium selenite was added to urine; whereafter the arsenic concentration was measured with method I. The results, shown in table 3 , indicate no influence on the analysis of arsenic up to a selenium level of $3 \mu \mathrm{mol} / \mathrm{l}$.

\section{Discussion}

The main urinary metabolites following exposure to inorganic arsenic are DMA, MMA, and inorganic arsenic. The present study demonstrates that rapid measurements of the sum of these metabolites can be made with a method based on a commercially available hydride generation kit attached to an AAS. The urine should not be pretreated before analysis. Sensitivity is high enough for the determination of arsenic concentrations that can be expected even in the urine of persons without excess exposure to arsenic.

The most important disadvantage of using total urinary arsenic as an indicator of exposure to inorganic arsenic is that seafood ingestion may introduce serious interference. Arsenic may occur in fish in the form of arsenobetaine $(6,9)$ or similar compounds, possibly combined with phospholipids $(2,7)$. Such compounds contain arsenic of quarternary structure with no reducible groups attached to the arsenic atom. It is therefore not likely that the arsenic compounds in seafood would pro- duce arsines under the present conditions. The results of this study confirm such an assumption. The measurement of inorganic and methylated arsenic acids with the arsine generation method is not influenced by arsenobetaine, arsenocholine, or other organic arsenic compounds present in shrimp. When the proposed method is used for assessing occupational exposure to inorganic arsenic, there is thus no need for restricting the intake of fish and seafood, which is definitely necessary when total urinary arsenic is measured.

The minor increase of inorganic and methylated arsenic in urine after shrimp are ingested is probably due to inorganic arsenic in the shrimp. Lunde (15) found that the concentration of inorganic arsenic (including organic-bound arsenic degraded by $6.6 \mathrm{M} \mathrm{HCl}$ ) was about $27 \mu \mathrm{mol} / \mathrm{kg}$ of dry weight, while that of organic arsenic compounds was about $470 \mu \mathrm{mol} / \mathrm{kg}$. Inorganic arsenic in the diet cannot be differentiated from inorganic arsenic of other sources. Buchet et al (5) reported values of arsenic (inorganic arsenic + MMA + DMA) of $1-12 \mu \mathrm{mol} / 1$ in the urine of exposed workers, a value which should be compared with the contribution of arsenic from dietary inorganic arsenic of about $0.1 \mu \mathrm{mol} / 1$, as found in the present study.

In a recent report Buchet et al (5) suggested that the speciation of inorganic arsenic, MMA, and DMA in urine, with the method described by Braman \& Foreback (4), is the most suitable for biologically monitoring workers exposed to inonganic arsenic. The method presented in this paper has several advantages over it and similar methods used for the selective analysis of the different urinary metabolites. It is fast and easy to use so that, 
even with a frequent determination of standards, about 40 urine samples may be analyzed per day.

Buchet et al (5) claimed that the speciation method could give information about the length of the time period between exposure and sampling of urine, since the ratio of inorganic arsenic to DMA decreases with time after exposure. However, this ratio is also dependent on the dose level. Reports on the urinary metabolites in humans and animals indicate that MMA and DMA together account for $80-90 \%$ of the total $48-\mathrm{h}$ urinary excretion at low exposure levels, but only $50-70 \%$ at high levels $(28,32,33)$. Therefore, calculations of the length of time between exposure and sampling will be uncertain if the dose level is not taken into account.

According to Hinners (11) the presence of DMA in a sample can cause an underestimation of the arsenic content when measured with the arsine generation/AAS method. However, the reported variations in relation to the chemical form of arsenic were probably due to the fact that the results were based on peak height measurements. The present study clearly shows that the results are independent of the chemical form of the measured arsenic provided that peak areas are recorded and not peak heights. Variations in the arsine generation speed will influence peak shape and height, but not peak area. Since the peak area per unit of arsenic is independent of the chemical form, any of the compounds measured can be used for standard solutions. With the speciation method of Braman \& Foreback (4), each metabolite requires its own standard solution made from that particular arsenic compound. The peak area per micromole of arsenic may differ for the various forms of arsenic because of differences in base properties giving rise to differences in the tendency to be permanently trapped in the cold trap.

Selenium, a possible source of interference in the arsine generation technique, occurs naturally in food, especially seafood and internal organs (17). Selenite does not influence arsenic measurements with the proposed method of concentrations up to $3 \mu \mathrm{mol} / \mathrm{l}$ (as elemental selenium). The normal level of selenium in human urine is $0.1-0.7 \mu \mathrm{mol} / \mathrm{l}(22,29)$.

\section{Acknowledgment}

This work was supported by grants from the Swedish Work Environment Fund $(79 / 55)$.

The valuable technical assistance of $\mathrm{Ms}$ M Sandström and Ms M Ståhlberg is gratefully acknowledged.

\section{References}

1. Andreae MO. Determination of arsenic species in natural waters. Anal chem 49 (1977) $820-823$.

2. Andreae MO, Klumpp D. Biosynthesis and release of organoarsenic compounds by marine algae. Environ sci technol 13 (1979) $738-741$.

3. Bencko V, Symon K. Health aspects of burning coal with a high arsenic content. Environ res 13 (1977) 378-385.

4. Braman RS, Foreback CC. Methylated forms of arsenic in the environment. Science 182 (1973) 1247-1249.

5. Buchet JP, Lauwerys $R$, Roels H. Comparison of several methods for the determination of arsenic compounds in water and in urine. Int arch occup environ health 46 (1980) $11-29$.

6. Cannon JR, Edmonds JS, Francesconi KA, Langsford JB. Arsenic in marine fauna. In: International conference: Management $\&$ control of heavy metals in the environment, London, September 1979. CEP Consultants Ltd, Edinburgh 1979, pp 283-286.

7. Cooney RV, Mumma RO, Benson AA. Arsoniumphospholipid in algae. Proc natl acad sci usa 75 (1978) 4262-4264.

8. Crecelius EA. Changes in the chemical speciation of arsenic following ingestion by man. Environ health perspect 19 (1977) $147-150$

9. Edmonds JS, Francesconi KA, Cannon JR, Raston CL, Skelton BW, White AH. Isolation, crystal structure and synthesis of arsenobetaine, the arsenical costituent of the Western rock lobster Panulirus Longipes Cygnus George. Tetrahedron lett 18 (1977) $1543-1546$.

10. Henry FT, Thorpe TM. Determination of arsenic (III), arsenic (V), monomethylarsonate and dimethylarsinate by differential pulse polarography after separation by ion exchange chromatography. Anal chem 52 (1980) $80-83$.

11. Hinners TA. Arsenic speciation: Limitations with direct hydride analysis. Analyst 105 (1980) $751-755$.

12. Irgolic KJ, Woolson EA, Stockton RA Newman RD, Bottino NR, Zingaro RA, Kearney PC, Pyles RA, Maeda S, McShane WJ, Cox ER. Characterization of arsenic compounds formed by Daphnia magna and Tetraselmis chuii from inorganic arsenate. Environ health perspect 19 (1977) 61-66. 13. Knechtel JR, Fraser JL. Preparation of a 
stable borohydride solution for use in atomic-absorption studies. Analyst 103 (1978) 104-105.

14. Lakso JU, Rose LJ, Peoples SA, Shirachi DY. A colorimetric method for the determination of arsenite, arsenate, monomethylarsonic acid and dimethylarsinic acid in biological and environmental samples. J agric food chem 27 (1979) $1229-1233$.

15. Lunde G. Separation and analysis of organic-bound and inorganic arsenic in marine organisms. J sci food agric 24 (1973) 1021-1027.

16. Lunde G. Occurrence and transformation of arsenic in the marine environment. Environ health perspect 19 (1977) $47-52$.

17. Morris VC, Levander OA. Selenium content of foods. J nutr 100 (1970) 1383-1388.

18. National Bureau of Standards. Standard reference material, 1571. Washington, DC 1977. (National bureau of standards certificate of analysis).

19. Pinto SS, Varner MO, Nelson KW, Labbe AL, White LD. Arsenic trioxide absorption and excretion in industry. $\mathbf{J}$ occup med 18 (1976) 677-680.

20. Samaan $\mathbf{S}$. Metallorganische Verbindungen As, Sb, Bi. Band XIII/8. In: Müller E, ed. Methoden der organischen Chemie. George Thieme Verlag, Stuttgart 1978, p 402.

21. Smith AE. Interference in the determination of elements that form volatile hydrides with sodium borohydride using atomic-absorption spectrophotometry and the argonhydrogen flame. Analyst 100 (1975) 300-306.

22. Smith TJ, Crecelius EA, Reading JC. Airborne arsenic exposure and excretion of methylated arsenic compounds. Environ health perspect 19 (1977) 89-93.

23. Talmi Y, Bostick DT. Determination of alkylarsenic acids in pesticide and environmental samples by gas chromatography with a microwave emission spectrometric detection system. Anal chem 47 (1975) $2145-2150$.

Received for publication: 4 November 1980
24. Tam GKH, Charbonneau SM, Bryce F, Pomroy C, Sandi E. Metabolism of inorganic arsenic $\left({ }^{74} \mathrm{AS}\right)$ in humans following oral ingestion. Toxicol appl pharmacol 50 (1979) 319-3:22.

25. Tam GKH, Charbonneau SIM, Lacroix G, Bryce F. Confirmation of inorganic arsenic and dimethylarsinic acid in urine and plasma of dog by ion-exchange and TLC. Bull environ contam toxicol 21 (1979) $371-374$.

26. Tam KH, Charbonneau SM, Bryce F, Lacroix G. Separation of arsenic metabolites in dog plasma and urine following intravenous injection of ${ }^{74} \mathrm{As}$. Anal biochem 86 (1978) 505-511.

27. Uthe JF, Freeman HC, Johnston JR, Michalik P. Comparison of wet ashing and dry ashing for the determination of arsenic in marine organisms, using methylated arsenicals for standards. $J$ assoc off anal chem 57 (1974) 1363-1365.

28. Vahter M. Biotransformation of trivalent and pentavalent inorganic arsenic in mice and rats. Environ res (in press).

29. Wester PO. Trace elements in serum and urine from hypertensive patients before and during treatment with chlorthalidone. Acta med scand 194 (1973) 505-512.

30. Westöö G, Ry.dälv M. Arsenic levels in foods. Vår föda 24 (1972) 21-40.

31. Woolson EA, Aharonson N. Separation and detection of arsenical pesticide residues and some of their metabolites by high pressure liquid chromatography-graphite furnace atomic absorption spectrometry. J assoc off anal chem 63 (1980) 523-528.

32. Yamauchi $H$, Yamamura $Y$. Dynamic change of inorganic arsenic and methylarsenic compounds in human urine after oral intake as arsenic trioxide. Ind health 17 (1979) $79-83$.

33. Yamauchi $H$, Yamamura $Y$. Urinary inorganic arsenic and methylarsenic excretion following arsenate-rich seaweed ingestion. Jpn $\mathrm{j}$ ind health 21 (1979) 47-54. 